\title{
KAJIAN GENESIS DAN DINAMIKA WILAYAH PESISIR KAWASAN KARST PULAU SEMPU KABUPATEN MALANG PROVINSI JAWA TIMUR
}

\author{
Bayu Argadyanto Prabawa1 ${ }^{1}$ Ahmad Cahyadi' ${ }^{3}$ Adrian Valentino T., \\ Dini Feti Anggraini ${ }^{4}$ \\ 1,2,4 Karst Student Forum Fakultas (KSF) Geografi Universitas Gadjah Mada \\ 1,2,4 Magister Perencanaan Pengelolaan Pesisir dan Daerah Aliran Sungai \\ (MPPDAS) Fakultas Geografi Universitas Gadjah Mada Yogyakarta \\ 2Jurusan Geografi Lingkungan Fakultas Geografi Universitas Gadjah Mada \\ ${ }^{3}$ Fakultas Filsafat Universitas Gadjah Mada Yogyakarta \\ Email: $\underline{1 \text { bayuarga@gmail.com; }}$ ahmadcahyadi@geo.ugm.ac.id
}

\section{INTISARI}

Penelitian ini bertujuan untuk (1) mengidentifikasi tipologi pesisir Pulau Sempu; (2) menjelaskan genesis pesisir Pulau Sempu; dan (3) menjelaskan berbagai macam dinamika pesisir Pulau Sempu. Metode penelitian dilakukan dengan membuat peta tentative tipologi pesisir Pulau Sempu berdasarkan pada peta RBI skala 1: 25.000 yang kemudian dilanjutkan dengan melakukan survey lapangan dengan purposive sampling dan mengelilingi Pulau Sempu dengan menggunakan kapal. Hasil penelitian menunjukkan bahwa (1) tipologi pesisir Pulau Sempu terdiri atas wave erosion coast, land erosion coast, structurally shaped coast, dan sub-aerial depositional coast,; (2) genesis pesisir Pulau Sempu diawali oleh proses pengangkatan yang meninggalkan jejak cliff, lalu terjadina erosi lahan dan abrasi oleh ombak yang meninggalkan jejak berupa rockfall dan stach, sedangkan genesis mangrove berasal dari substrat lumpur hasil erosi perbukitan; dan (3) dinamika pesisir timur dan selatan Pulau Sempu didominasi oleh proses geodinamika tektonik pada masa lampau dan hidrodinamika ombak dan gelombang laut pada masa sekarang, pesisir barat didominasi oleh morfodinamika erosi dan hidrodinamika gelombang laut, sedangkan pesisir utara bekerja morfodinamika erosi dan sedimentasi.

Kata Kunci : Tipologi Pesisir, Genesis, Dinamika, Pulau Sempu

\section{PENDAHULUAN}

\section{Latar Belakang}

Indonesia adalah negara kepulauan terbesar di dunia yang memiliki 17.508 pulau, dan memiliki garis pantai terpanjang kedua di dunia setelah Kanada (Christanto, 2010 dan Supriharyono, 2009). Sumber daya alam Indonesia meliputi \pm 193 juta hektar daratan dan \pm 500 juta hektar lautan, dan didalamnya terkandung sumber daya alam hayati lebih dari 25.000 jenis tumbuhan dan 400.000 jenis binatang dan berbagai biota perairan yang belum banyak diketahui, serta 70 tipe ekosistem yang berpotensi dalam menunjang 
kehidupan umat manusia pada umumnya dan rakyat Indonesia pada khususnya (Departemen Kehutanan, 1992). Sebagai negara berbentuk kepulauan tentunya dari masing-masing pulau memiliki suatu keunikan sumber daya alam yang beragam. Keunikan ini adalah sebuah potensi yang memiliki nilai signifikan bagi peradaban manusia dan peradaban alam di sekitarnya.

Kekayaan Indonesia sebagai negara maritim yang strategis merupakan suatu kekayaan yang penting dan harus dijaga kelestariannya. Salah satukekayaan alam yang dimiliki Indonesia adalah Pulau Sempu. Pulau Sempu terletak diantara $112^{\circ} 40^{\prime} 45^{\prime \prime}$ - $112^{\circ} 42^{\prime} 45^{\prime \prime}$ bujur timur dan $8^{\circ} 27^{\prime} 24^{\prime \prime}-8^{\circ} 24^{\prime}$ 54" lintang selatan (Tanaem dkk, 2012). Pulau Sempu terletak di perairan Samudera Hindia yang secara administratif termasuk ke dalam desa Tambakrejo, Kecamatan Sumbermanjing Wetan, Daerah Tingkat II Kabupaten Malang, Provinsi Jawa Timur.

Berdasarkan SK, GB No. 46 Stbl. 1928 No. 69 Tahun 1928, Pulau Sempu ditetapkan sebagai kawasan cagar alam. Kawasan ini memiliki luas 877 hektar. Penetapan Pulau Sempu sebagai kawasan cagar alam karena keadaan alamnya yang khas, juga diperuntukkan bagi kepentingan penelitian dan ilmu pengetahuan. Pulau Sempu menyimpan kekayaan tentang rahasia alam, tumbuhan, maupun satwa yang berguna bagi manusia dan perlu digali dari alam yang masih utuh (Departemen Kehutanan, 1992).

Salah satu keunikan Pulau Sempu adalah keindahan wilayah pesisirnya. Wilayah pesisir Pulau Sempu memiliki potensi besar, baik sebagai obyek wisata (rekreasional) ataupun sebagai media pembelajaran dan penelitian tentang alam. Bentuklahan Pulau Sempu sebagai pulau kecil berbatuan karbonat memiliki karakteristik tersendiri dalam pembentukannya, bentukan di dalamnya, dan proses yang bekerja di dalamnya. Proses solusional batugamping yang membentuk morfologi karst pada pulau ini menjadikan keunikan tersendiri. Hal ini tentu saja memunculkan potensi tersendiri dari Pulau Sempu.

Pengetahuan mengenai potensi dan ancaman bahaya dalam suatu wilayah pesisir diperlukan dalam arahan pengembangan mengenai sebuah wilayah pesisir (Gornitz, 1991; Pamela dkk, 2010; Marfai dan Cahyadi, 2012), dalam hal ini adalah wilayah pesisir Pulau Sempu. Sebelum mengetahui berbagai potensi dan ancaman bahaya wilayah pesisir, maka diperlukan kajian tentang genesis wilayah pesisir dan dinamika pesisirnya (Gunawan, dkk, 2005). Kajian tentang genesis dan dinamika wilayah pesisir pulau Sempu dianggap penting karena dapat digunakan untuk mengetahui asal-usul pembentukan Pulau Sempu, mengetahui berbagai proses geologi dan geomorfologi yang bekerja di dalamnya, dan memprediksi berbagai kejadian yang mungkin terjadi di Pulau Sempu. Namun demikian, masih sedikitnya data mengenai wilayah pesisir Pulau Sempu dirasa penulis mengakibatkan kurangnya pengetahuan masyarakat sekitar mengenai kekayaan alam pesisir Pulau Sempu. Hal ini menyebabkan kurang optimalnya masyarakat dalam memanfaatkan kekayaan alam dan menjaga kelestarian pesisir pulau Sempu 
(Tanaem dkk, 2012). Berdasarkan hal ini penulis merasa perlu untuk melakukan kajian mengenai genesis dan dinamika pesisir pulau Sempu.

\section{Tujuan Penelitian}

Penelitian ini bertujuan untuk:

1. Mengidentifikasi tipologi pesisir Pulau Sempu;

2. Menjelaskan genesis pesisir Pulau Sempu; dan

3. Menjelaskan berbagai macam dinamika pesisir Pulau Sempu.

\section{TINJAUAN PUSTAKA}

Tipologi pesisir adalah pembagian tipe pesisir berdasarkan genesa pembentukan pesisir dan proses yang berlangsung di dalamnya (Shepard, 1972 dalam Gunawan, 2005). Konsep tipologi dikemukakan oleh Shepard (1972) yang membagi tipologi pesisir menjadi dua, yaitu tipologi primer dan sekunder. Tipologi pesisir primer adalah tipologi pesisir yang morfologinya lebih terbentuk oleh proses-proses terestrial seperti erosi, vulkanisme, deposisi, dan diatropisme ketimbang proses marin dan organisme, sedangkan tipologi pesisir sekunder adalah tipologi pesisir yang morfologinya lebih terbentuk karena aktivitas organisme dan proses marin (Gunawan dkk, 2005). Tipologi primer terdiri atas Land Erosion Coast, Sub Aerial Deposition Coast, Structurally Shaped Coast, dan Vulcanic Coast, sedangkan tipologi pesisir sekunder terdiri atas Marine Deposition Coast, Wave Erosion Coast, dan Coast Built by Organism.

Tipologi pesisir menunjukkan genesis dan dinamika pesisir yang terjadi pada suatu wilayah pesisir. Setiap tipologi pesisir memiliki karakteristik proses pembentukan dan dinamika pesisirnya masing-masing (Bachtiar dkk, 2012; Marfai dan Cahyadi, 2012). Lebih lanjut Marfai dan Cahyadi (2012) menyebutkan bahwa tipologi bencana sangat erat kaitannya dengan tipe,karakteristik dan kerawanan bencana yang munkin terjadi di suatu pesisir.

\section{METODE PENELITIAN}

Metode penelitian terdiri atas langkah-lagkah dalam pengumpulan data, pengolahan data, dan analisis data untuk memecahkan permasalahan yang diangkat dalam penelitian. Penelitian dilakukan di wilayah pesisir Pulau Sempu, desa Sendang Biru, kecamatan Sumbermanjing Wetan, Kabupaten Malang, jawa Timur. Alat dan bahan yang digunakan adalah peta RBI Lembar Sitiarjo skala 1:25.000, Arc GIS 9.3 dan Global Mapper 10 sebagai perangkat lunak pembuatan peta, kompas geologi, GPS (Global Positioning System), dan kamera. Langkah awal yang dilakukan adalah perisapan data lapangan yaitu pembuatan peta tentatif tipologi pesisir Pulau Sempu menggunakan peta RBI Lembar Sitiarjo skala 1:25.000 yang akan digunakan sebagai acuan dalam proses pengambilan sampel. Pengumpulan data dilakukan dengan survey lapangan dengan metode pengambilan sampel menggunakan purposive sampling berdasarkan titik sampel yang telah dipilih pada peta tentatif tipologi pesisir. Survey lapangan dilakukan dengan cara mendatangi tiap sampel yang 
telah ditentukan, baik dengan cara susur pantai maupun dengan mengelilingi pulau dengan kapal.

\section{HASIL DAN PEMBAHASAN \\ Tipologi Pesisir Pulau Sempu}

Pesisir pulau Sempu memiliki beberapa macam tipologi, yaitu tipe wave erosion coast, land erosion coast, structurally shaped coast, dan sub-aerial depositional coast. Penulis membagi wilayah pesisir Pulau Sempu menjadi empat bagian, yaitu pesisir utara, barat, timur, dan selatan. Pesisir utara Pulau Sempu memiliki beberapa tipologi pesisir, namun yang paling mendominasi adalah tipe wave erosion coast yang dibuktikan dengan adanya cekungancekungan dan jatuhan batugamping pada bagian bawah tebing pesisir bagian utara pulau. Selain itu juga terdapat tipe land erosion coast, yaitu tipe pesisir yang terbentuk karena adanya erosi pada lahan bawah di daratan. Tipologi pesisir ini dapat dijumpai pada teluk Semut yang merupakan pintu masuk bagi pengunjung pulau Sempu. Tipologi ini dapat dikenali dari adanya bukti-bukti erosi pada wilayah darat teluk Semut. Selain itu, teluk Semut juga memiliki tipologi sub aerial depositional coast dengan adanya mangrove pada teluk ini.

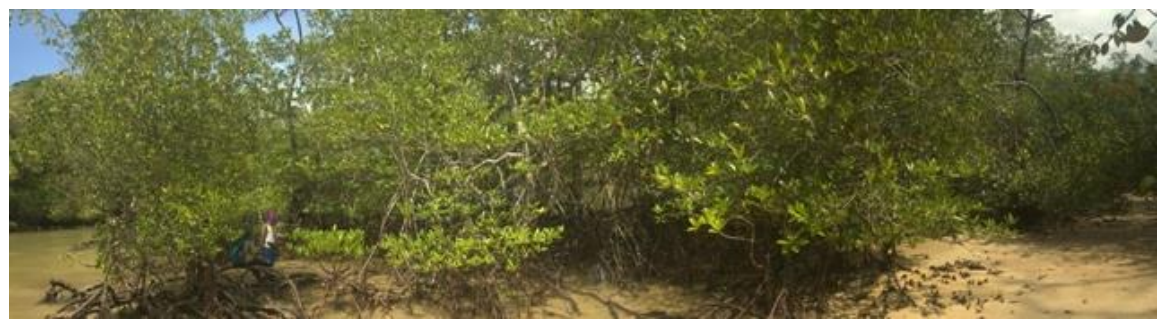

Gambar 1. Ekosistem mangrove pada Teluk Semut (koleksi Argadyanto, 2011)

Pesisir bagian timur pulau Sempu memiliki tipologi pesisir structurally shaped coast dan wave erosion coast. Pesisir bagian timur terdiri atas tebing pantai yang tegak (cliff) yang memanjang dan jatuhan-jatuhan batuan (stach) di bawahnya yang menunjukkan bukti proses pengangkatan kerak bumi dan adanya pengaruh angin maupun gelombang dari laut.

Pesisir selatan Pulau Sempu memiliki tipologi pesisir structurally shaped coast, land erosion coast, dan wave erosion coast. Bagian pesisir selatan pulau Sempu yang terkenal adalah Segara Anakan. Segara Anakan adalah sebuah bentukan laguna yang terjebak di daratan. Segara Anakan memiliki tipologi pesisir structurally shaped coast. Pantai lain yang berada di selatan pulau adalah Pasirpanjang dan Baru-Baru. Pantai ini memiliki tipologi land erosion coast dan wave erosion coast, buktinya adalah adanya mushroom rock (batu berbentuk jamur) di pantai baru-Baru. 


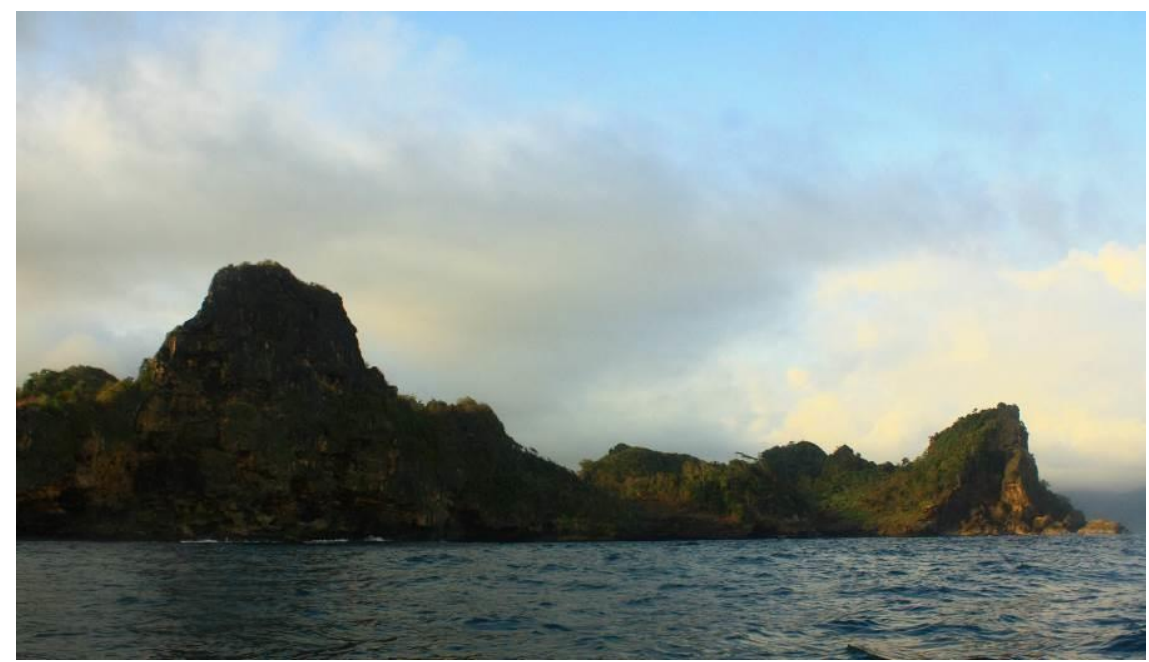

Gambar 2. Tipologi structurally shaped coast pesisir timur Pulau Sempu (koleksi Argadyanto, 2011)

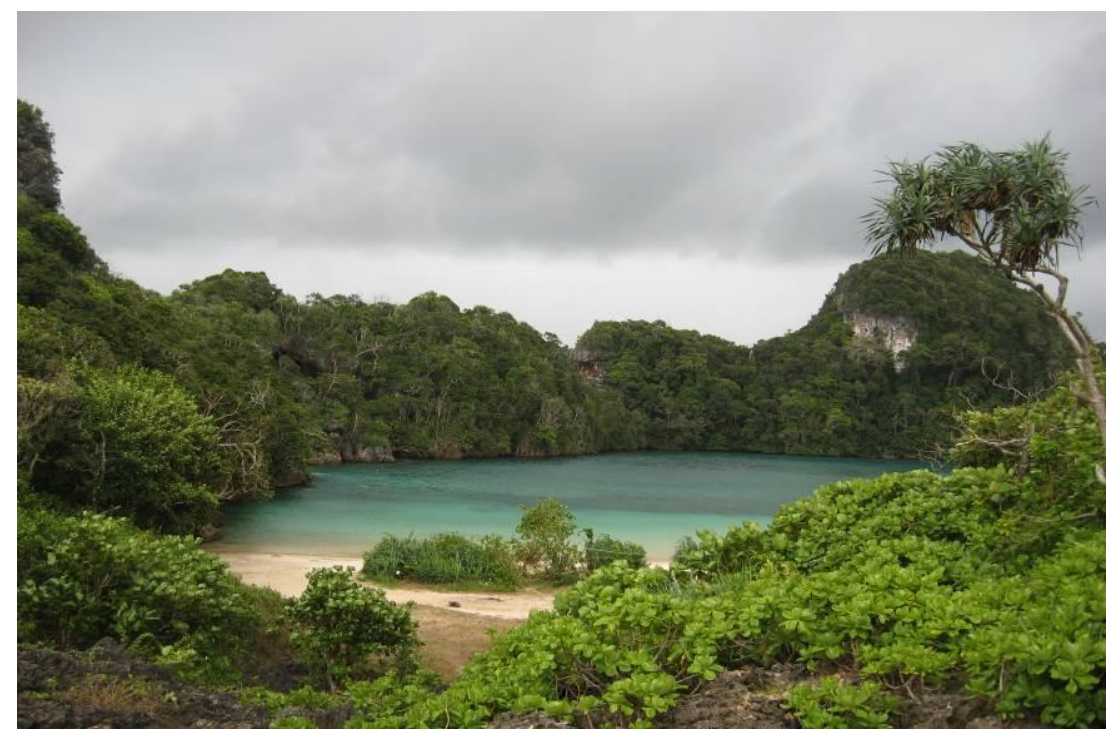

Gambar 3. Laguna Segara Anakan (Tanaem dkk, 2012)

Pesisir barat didominasi oleh land erosion coast dan wave erosion coast. Hampir sebagian besar pantai di pesisir barat memiliki bentuk dan tipologi yang sama.Tipologi structurally shaped coast juga ditemui di pesisir barat pulau dengan adanya sea cave dan cliff pada dinding teluk Raas. 
Dinamika yang bekerja pada pesisir barat pulau Sempu adalah dinamika ombak dan erosi lahan pada bukit-bukit di pinggir pantai.

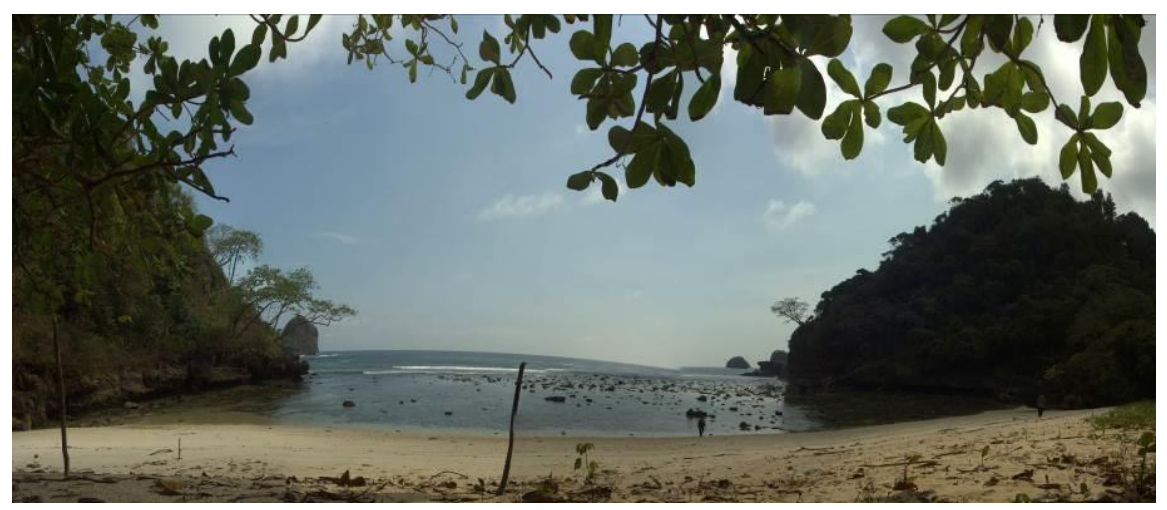

Gambar 4. Tipologi kompleks land erosion coast dan wave erosion coast pesisir barat Pulau Sempu (koleksi Argadyanto, 2011)

Genesis pesisir Pulau Sempu dimulai dari proses tektonik yang menyebabkan pengangkatan lempeng benua. Proses pengangkatan ini menyebabkan zona terumbu karang terangkat ke permukaan dan membentuk lapisan batugamping yang merupakan material pembentuk Pulau Sempu. Jejak proses tektonik ini ditunjukkan oleh tipologi structurally shaped coast pada pesisir timur dan selatan pulau.

Dinamika pesisir yang berjalan adalah proses geodinamik. Perkembangan dari tipologi structurally shaped coast adalah tipologi wave erosion coast, dimana batuan-batuan pada cliff akan terabrasi ombak dan gelombang dan mejadi rockfall dan stach. Dinamika pesisir yang terjadi adalah proses hidrodinamika oleh ombak dan gelombang laut. Proses morfodinamika erosi tanah dan sedimentasi juga berperan dalam perkembangan pesisir Pulau Sempu. Dinamika erosi dan sedimentasi sebagian besar terjadi pada pesisir bagian utara, barat, dan selatan Pulau Sempu. Proses morfodinamika ini membentuk tipologi land erosion coast dan sub aerial deposition coast. Perpaduan dua tipologi ini sangat terlihat pada pesisir timur Pulau, pada teluk Semut. Erosi lahan pada bukit-bukit mengakibatkan sedimentasi lumpur pada pesisir, sedimen lumpur ini merupakan substrat bagi mangrove yang tumbuh disana. Dinamika pesisir lain yang terjadi adalah ekodinamika perkembangan mangrove di pesisir utara Pulau Sempu. 


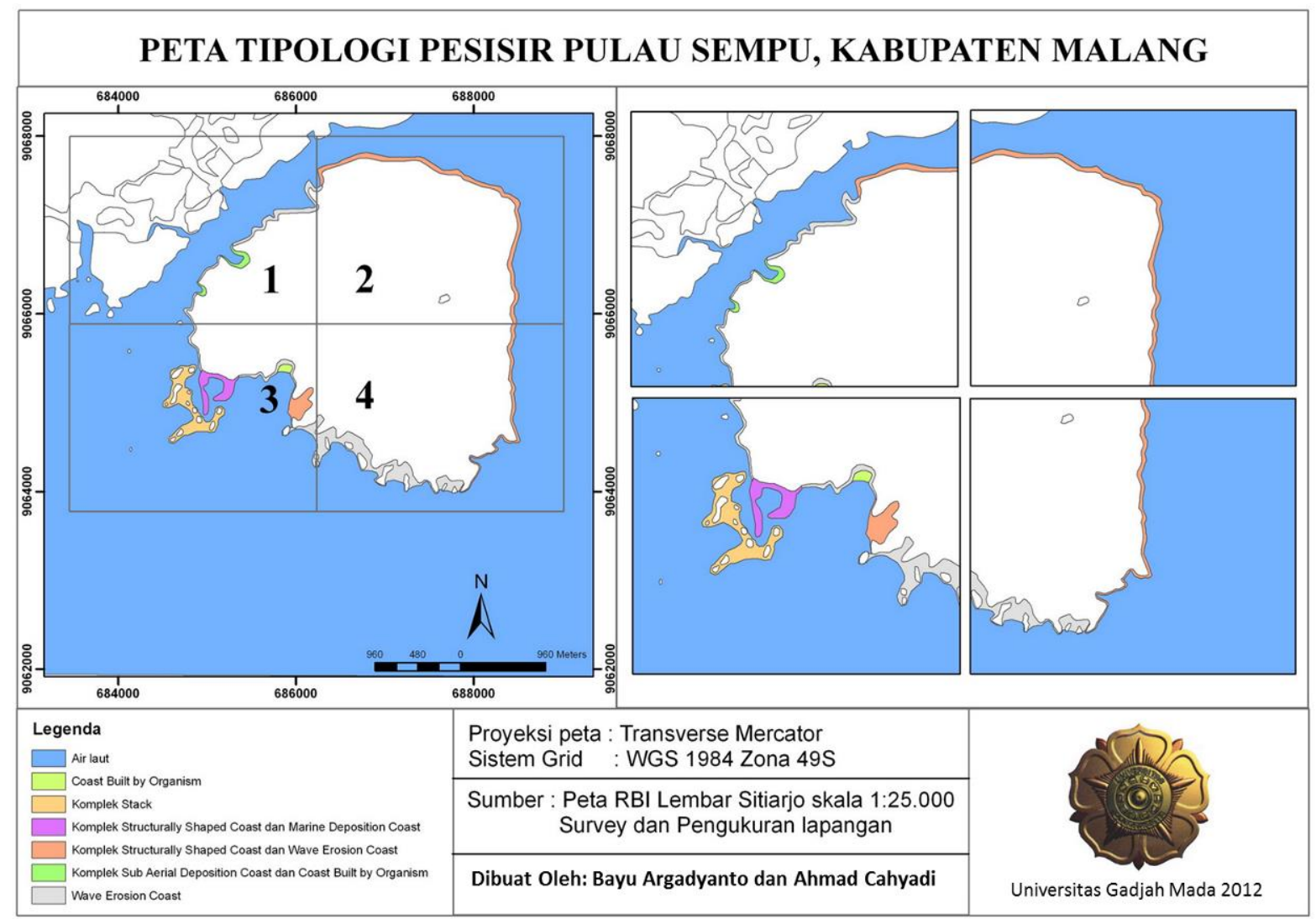

Gambar 5. Peta Tipologi Pesisir Pulau Sempu 


\section{KESIMPULAN}

Berdasarkan hasil kajian yang telah dilakukan, maka dapat disimpulkan beberapa hal berikut ini:

1. Tipologi pesisir Pulau Sempu terdiri atas wave erosion coast, land erosion coast, structurally shaped coast, dan sub-aerial depositional coast.

2. Genesis pesisir Pulau Sempu diawali oleh proses pengangkatan yang meninggalkan jejak cliff, lalu terjadina erosi lahan dan abrasi oleh ombak yang meninggalkan jejak berupa rockfall dan stach. Genesis mangrove berasal dari substrat lumpur hasil erosi perbukitan.

3. Pesisir timur dan selatan Pulau Sempu didominasi oleh proses geodinamika tektonik pada masa lampau dan hidrodinamika ombak dan gelombang laut sekarang. Pesisir barat didominasi oleh morfodinamika erosi dan hidrodinamika gelombang laut. Pesisir utara bekerja morfodinamika erosi dan sedimentasi.

\section{DAFTAR PUSTAKA}

Bachtiar, W.M.; Cahyadi, A. dan Dipayana, G.A. 2012. Indeks Kerentanan Kepesisiranterhadap Kenaikan Muka Air Laut Pada Beberapa Tipologi Kepesisiran Di Propinsi Daerah Istimewa Yogyakarta. Prosiding Seminar Nasional Penginderaan Jauh dan Sistem Informasi Geografis 2012. 12 januari 2012. Fakultas Geografi Universitas Muhammadiyah Surakarta.

Christanto, Joko. 2010. Pengantar Pengelolaan Berkelanjutan Sumberdaya Wilayah Pesisir dan Pulau-Pulau Kecil. Yogyakarta: Deepublish.

Departemen Kehutanan, 1992. Konservasi Sumber Daya Alam Hayati dan

Ekosistemnya. Jakarta: Biro Hubungan Masyarakat Sekretariat Jenderal Departemen Kehutanan.

Gornitz, V. 1991. Global Coastal Hazards from Future Sea Level Rise. Palaeogeography, Palaeoclimatology, Palaeoecology (Global and Planetary Change Section), 89. Hal: 379-398. Elsevier Science Publishers B.V., Amsterdam.

Pamela, A., Abuodha, O., dan Woodroffe, C.D. 2010. Assessing Vulnerability to Sea-Level Rise Using A Coastal Sensitivity Index: A Case Study from Southeast Australia. Jurnal Coast Conservation, 14. Hal: 189-205. Springer.

Gunawan, T.; Santosa, L.W.; Muta'ali, L.; dan Santosa, S.H.M.B. 2005. Pedoman

Survei Cepat Terintegrasi Wilayah Kepesisiran. Yogyakarta: Badan Penerbit dan Percetakan Fakultas Geografi (BPFG).

Tanaem, A.V.; Cahyadi, A.; Argadyanto, B.; Endarto, R. dan Khoirizzaad. 2012. Geodiversity And Biodiversity Potential For Development Of Sempu Island Around Communities. Makalah dalam International Conference On Sustainable Development. Universitas Mahasaraswati Denpasar, University of Florida dan Bansomdejchaophraya Rajabhat University. 6 Maret 2012 Sanur, Bali. 
Supriharyono. 2009. Konservasi Ekosistem Sumberdaya Hayati di Wilayah Pesisir dan Laut Tropis. Yogyakarta: Pustaka Pelajar.

Makalah ini merupakan salah satu chapter dalam buku berjudul "Ekologi Lingkungan Kawasan Karst Indonesia: Menjaga Asa Kelestarian Kawasan Karst Indonesia", dengan Editor Sudarmadji, Eko Haryono, Tjahyo Nugroho Adji, M. Widyastuti, Rika Harini, Emilya Nurjani, Ahmad Cahyadi, Henky Nugraha. Buku ini diterbitkan di Yogyakarta Tahun 2013 oleh Penerbit Deepublish. Makalah ini dimuat di halaman 59-65. 